\title{
Projetos em waterfronts na era do empresariamento urbano: o caso do Porto Maravilha e da gentrificação da zona portuária carioca.
}

Waterfronts projects in the era of urban entrepreneurship: the case of Porto Maravillha and the gentrification of the Rio port area.

\section{Arthur Oliveira*}

*Arthur Oliveira: Arquiteto e Urbanista (Universidade Presbiteriana Mackenzie SP, 2011-2016), Mestre em Gestão Urbana (Pontifícia Universidade Católica do Paraná PPGTU, 2018-2020). Projetos de pesquisa e temas de interesse: Gestão Urbana; Planejamento urbano e regional; Grandes Projetos Urbanos; Áreas Pós-Industriais; Brownfields; Cidade Pós-Industrial, au.oliveirarthur@gmail.com

\section{Palavras-chave:}

Projetos Urbanos;

Rio de Janeiro;

Frentes d'água.

\section{Keywords:}

Urban Projects;

Rio de Janeiro;

Waterfronts.

\begin{abstract}
Resumo
presente artigo tem como objetivo discutir as relações entre o conceito de empresariamento e os projetos que se propõem a renovar as frentes d'água das cidades contemporâneas. Divide-se o texto em duas partes centrais: (1) que enfoca sobre as transformações procedentes da reestruturação capitalista e os vínculos desse processo com a origem, o conceito e a evolução histórica de projetos urbanos em waterfronts; e (2) que analisa o caso do projeto Porto Maravilha, discutindo suas relações com a exposição teórica, mas focalizando sobre os reflexos de gentrificação sobre a zona portuária carioca. Essa investigação apontou, sobretudo, que os resultados almejados pela intervenção urbana não alcançaram fins socialmente congruentes, tornando populações vulnerabilizadas deste território, direta ou indiretamente, as mais afetadas pelo projeto. A experiência carioca serve, deste modo, para apontar elementos cruciais que devem ser analisados em intervenções desse porte nas cidades, destacando, fundan
\end{abstract} ções pré-existentes.

\section{Abstract}

This article aims to discuss the relationship between the concept of entrepreneurship and the projects that propose to renew the waterfronts of contemporary cities. Therefore, the text is divides in two central parts: (1) which focuses on urban transformations arising from capitalist restructuring and the links of this process with the origin, concept and historical evolution of urban projects on waterfronts; (2) which analyzes the Porto Maravilha case, discussing its relations with the theoretica exhibition, but highlighting the reflexes of gentrification that it has produced over the Rio de Janeiro port area. This investigation pointed out, ends, making the vulnerable populations of this territory, directly or indirectly, the most affected by the intervention. The Rio de Janeiro experience, therefore, serves to point out crucial elements that must be analyzed in projects of this size, highlighting the social and urban insertion of pre-existing ones. 


\section{Introdução}

A partir das últimas décadas do século XX, iniciou-se, no modo de produção capitalista em nível global, uma série de modificações em diferentes escalas e conjunturas. Tais modificações, as quais culminaram em uma expressiva reestruturação econômica, produtiva e financeira - se tornaram, sobretudo a partir da crise de $1973^{1}$, cada vez mais constantes - primeiro entre as economias centrais e posteriormente entre as economias periféricas -, podendo ser apercebidas como fruto de uma reação do capital frente à crise através da redução do valor da força de trabalho e do aumento intensivo de novas estratégias de acumulação. No que se refere às cidades e à produção do seu espaço, conforme apontam Hall (2007) e Harvey (1996), essa reação capitalista refletiu sobremaneira no funcionamento econômico dos poderes públicos, configurando, maiormente, uma modificação gradual das políticas urbanas e da própria atuação do urbanismo a partir dos anos 1980, quando passa a convergir estratégias exponencialmente empresariais em função das novas perspectivas "pós-industriais" que passaram a dominar os âmbitos econômico, produtivo e social.

Esse novo urbanismo corrente, substancialmente verificado após década de 1980, pode ser lido e identificado, precipuamente, como novas formas de planejamento e gestão do espaço, seguindo, quase sempre, a lógica empresarial e mercantilizada. Com essa lógica firmada, que passa a ser desenvolvida em diversas cidades - sobretudo nos países centrais - paulatinamente casos como Barcelona, Baltimore e Londres se transformam em espécimes globais de boa gestão urbana, instigando inúmeras realidades citadinas em seus processos de readequação pós-arrefecimento industrial. Percebe-se assim, que o planejamento e a gestão pública - enquanto prática - assumem uma espécie de transmutação, adquirindo novas características e se distanciando, gradualmente, do gerenciamento e da regulamentação estatal predominantes no seu passado modernista, centralista e tecnocrático. Grosso modo, há uma promoção empresarial da cidade, que sob o viés do crescimento econômico, busca constantemente a atração de investimentos dinamizadores como signo resolutivo das contradições contemporâneas.
Passa, portanto, a se tornar comum entre as realidades urbanas, a promoção de uma imagem renovada de si mesmas, calcada sob uma lógica de competição e disputa pela atração de fluxos financeiros. Por conseguinte, a reconstrução da cidade, o desenho de novos espaços e a remodelação de determinados setores subutilizados pelo arrefecimento fordista keynesiano - como as frentes d'água, portos, centros históricos e áreas centrais em geral -, não só se converteram em elementos usuais do molde urbano empresarial, como passaram a modificar a estrutura física e simbólica das cidades. Em outras palavras, a transição do gerenciamento ao empresariamento pode ser percebida pela modificação da administração pública, beneficiando investimentos privados no âmbito local - visando a maior competitividade e atração de investimentos móveis e flexíveis - e difundindo publicitariamente sua imagem em uma perspectiva mercantilizada.

Este estudo dispõe-se, além de discutir as relações entre o conceito de empresariamento e os projetos que se propõem a renovar as frentes d'água das cidades contemporâneas, analisar, através do caso Porto Maravilha, o processo de gentrificação que foi e tem sido consubstanciado na zona portuária carioca. Em meio as questões aqui levantadas, destacam-se os impactos desfavoráveis do projeto - no tocante a inclusão social e urbana - simbolizados notadamente por: (1) remoções diretas e indiretas exercidas através de programas habitacionais; (2) elevadas pressões relacionadas ao aumento da precificação da terra na zona portuária; e (3) aumento das técnicas e práticas de militarização e controle do espaço como saída resolutiva da questão urbana dos morros e favelas, e especificamente das áreas favelizadas adjacentes ao porto carioca.

Inicia-se, portanto, esta proposição textual com uma análise do decurso do empresariamento nas cidades contemporâneas - aquelas cujos setores industriais atravessaram subutilizações e obsolescências - e as relações desse processo com projetos de transformação urbana que visam, sobretudo, a reintegração de territórios obsoletos das cidades com os fluxos de capitais globais. Em seguida, versa-se sobre os projetos em waterfronts, primeiro chamando atenção para suas origens e conceitos, e depois, para sua evolução histórica, assinalada desde os anos 1960 e

1A crise de 1973, mais conhecida como "crise do petróleo", teve início quando os membros integrantes da Organização dos Países Árabes Exportadores de Petróleo (OPEP), estabeleceram embargo petrolífero endereçado as nações apoiadoras da guerra de Yom Kippur em Israel. 
1970. Por fim, discute-se como determinados reflexos produzidos pelo projeto Porto Maravilha associados a diferentes programas de governo exercidos por distintas gestões predecessoras, vêm impulsionando a gentrificação de populações pré-existentes nos aproximados 5 milhões de metros quadrados que compõem a zona portuária do Rio de Janeiro.

\section{Cidade pós-industrial, rugosidades e o empresariamento urbano}

Ao longo do século $\mathrm{XX}$, diversas cidades pelo mundo vivenciaram expressivos processos de crescimento urbano e econômico, os quais calcados na soberania da matriz fabril-fordista, pautaram a produção do espaço urbano sob o signo da segregação funcional e social (LIPIETZ, 1974). A essa segregação atribui-se a prerrogativa funcionalista e tecnocrática do urbanismo modernista que tinha o Estado como fundamental atuante no que se refere a gestão e ao planejamento do território, sendo esse um dos principais responsáveis por orientar, especialmente por meio do zoneamento, a ascensão de uma monofuncionalidade territorial que conferiu para as cidades industriais um modus de produção do espaço regulado, hierarquizado e gerenciado (DEL RIO, 2001; MARQUES, 2018). A cidade industrial fordista que se materializara fundamentalmente no pós-guerra foi, portanto, pautada por uma setorização geográfico-espacial funcionalista, e de acordo com Dias e Neto (2004), estabeleceu a concentração de funções como principal padrão observável.

A partir da década de 1970, alicerçado em fenômenos e acontecimentos substanciais como a crise do petróleo, a divisão internacional do trabalho e a ascensão de governos neoconservadores nos países centrais, tais cidades experimentaram uma série de mudanças cruciais no que se refere a sua organização e à produção de seu espaço, impactando âmbitos sociais, produtivos, de consumo, e reconfigurando, consequentemente, sua lógica funcionalista e tecnocrática. Emerge, portanto, dessa transfiguração, a percepção de uma cidade dita "pós-industrial" ou em processo de desindustrialização - ainda que tal generalização terminológica só possa ser contextualizada em poucas realidades urbanas centrais - que na prática rompe com a monofuncionalidade, abre caminho ao policentrismo e dá lugar a uma cada vez maior competitividade global de padrões empresariais, que estabelece uma quase que consensual perspectiva favorável a usos mistos e a um tipo de arquitetura contemporânea como emblema da mercantilização urbana.
Para entender melhor esse processo transitório concernente à emergência desse desenvolvimento urbano pós arrefecimento industrial, destaco dois conceitos abordados pela geografia crítica de Milton Santos e David Harvey, os quais se fazem significativos para o entendimento dessa transmutação entre espaço e tempo: o conceito de rugosidade e o conceito de empresariamento urbano. Entendendo, portanto, a cidade e a produção de seu espaço como elementos ligados aos fluxos globais e locais, os quais compõem o todo e, portanto, estão suscetíveis a alterações na medida em que o capital se transforma (BARTOLY, 2011; SCHNEIDER, 2015) - percebe-se como reflexo marcante da pós-industrialização no ambiente urbano a afirmação da temporalidade. Essa temporalidade pode ser entendida como um produto de diversas divisões internacionais do trabalho ao longo da história da humanidade, sendo a cidade o plano de fundo material e o resultado espacial desse processo que deriva das relações entre o homem e o meio ao longo de sua existência.

Conforme apontado Santos (2006, p.92), chama-se de rugosidade urbana aquilo que fica no passado enquanto forma, ou seja, refere-se aquilo que "resta do processo de supressão, acumulação e superposição, com que as coisas se substituem e se acumulam em todos os lugares". As rugosidades são, portanto, na cidade "pósindustrial" marcas da temporalidade de uma relação entre o homem e o meio que constituem resistência ao mundo contemporâneo. Neste trabalho, mesmo entendendo que o conceito de Santos (2006) possa se referir a quaisquer temporalidades ou momentos históricos do homem e do meio, destaco e enfatizo as rugosidades urbanas ligadas aos usos de matriz fordista - sobretudo de áreas industriais e portuárias - as quais no pós-guerra representaram importância medular para as cidades e que ao final do século $X X$ foram arrefecidas pelas prerrogativas tecnológicas e informacionais do capitalismo contemporâneo.

As rugosidades industriais e portuárias são, deste modo, produto de uma divisão do trabalho vivenciada na cidade industrial que foi e está em processo de superação, mas que continua, na contemporaneidade, a declarar sua materialidade, mesmo que de forma subutilizada ou obsoleta. Essas rugosidades revelam ainda uma desconexão desses espaços com os fluxos de capital predominantes pós anos 1970 e que se fazem essencialmente presentes na cidade "pós-industrial" globalizada. Em vista dessa desconexão do meio com os fluxos, emergem estratégias no âmbito da 
produção das cidades que se referem a uma busca em transformar esses "espaços" de rugosidade em "lugares"- entendendo aqui o conceito de "lugar" pela sua conexão com os fluxos e com o todo - mas, sobretudo, de reconectar os mesmos com a lógica contemporânea de produção do espaço mercantilizado.

Sobre essa reconexão das rugosidades com as lógicas contemporâneas de produção do espaço, ressalto, do mesmo modo, o conceito de "empresariamento urbano" apontado por David Harvey (1996), o qual elucida de maneira clara essa relação. Segundo o geógrafo, o entendimento e a concepção do espaço urbano como uma empresa, surge como uma alternativa para as cidades de matriz fabril-fordista, que arrefecidas pelas transformações do último quarto do século XX, buscavam se readequar localmente e globalmente às novas lógicas econômicas predominantes. $O$ conceito tem por base a valorização dos poderes locais e globais em detrimento do poder do Estado, visando a captação de investimentos pela negociação entre o capital financeiro internacional e os municípios, expressando assim uma busca constante de investimento, lucro e consumo no que se refere à produção do espaço.

À vista disso, as cidades passam a se tornar agentes e produtos que precisam, constantemente, se adaptar aos padrões estabelecidos pelas lógicas capitalistas predominantes, se utilizando, para isso, das regras estabelecidas pelo empresariamento para orientar reformas urbanísticas de adequação espacial e simbólica do espaço. A rigor, as cidades para prosperarem, deveriam ter um funcionamento empresarial, concorrendo entre si mesmas pela atração de capitais e construindo, para isso, uma flexibilidade e uma exceção de atuação e de discurso de seus protagonistas. A nova e principal função das gestões urbanas e dos governos locais nessa concepção, passaria a ser, portanto, a administração da opinião da população e dos contratos privados, visando convergir e proporcionar um plano de fundo propício e conveniente a negócios e à inserção da cidade no contexto mundial.

Governos locais, por meio de ações e iniciativas empresariais, passaram então a vislumbrar em determinadas rugosidades reconexões com os fluxos - sob cenário atrativo e favorável a negócios e aos mercados privados - por meio de projetos de transformação e inserção desses espaços subutilizados na lógica global e financeirizada. Conforme apontado por Del Rio (2001), os novos padrões de planejamento e produção do espaço das cidades pós-industriais globais não poderiam ignorar por razões óbvias - o potencial do patrimônio instalado, da acessibilidade e do simbolismo das áreas centrais das cidades. Essas áreas, as quais são em grande parte rugosidades que ainda se afirmam espacialmente no meio, se tornam, na lógica empresarial, mercadoria, sendo operadas por estratégias de branding e marketing, numa espécie de competição intra e interurbana pela atração de investimentos privados. Este novo contexto levou e ainda leva muitas cidades, em distintos momentos, a perseguir o renascimento de suas rugosidades através de projetos empresariais de transformação e realocação desses espaços nas lógicas globais da contemporaneidade urbana.

Neste artigo, enfatiza-se as rugosidades relacionadas a áreas portuárias de frentes d'água das cidades, conhecidas concomitantemente pela literatura como waterfronts. Esses espaços, os quais continuadamente mantiveram fortes relações com os centros urbanos, sempre trabalharam lado a lado para a proeminência e o êxito das cidades. Nada obstante, de acordo com Marques (2018), a partir do decurso empresarial - a qual é acompanhada da modernização dos meios de transporte e produção - os portos distanciaram-se dos centros urbanos, realocando-se para as bordas e para áreas de maior diálogo com os padrões produtivos contemporâneos. A extinção, modificação e o desenvolvimento tecnológico de grande parte das funções portuárias foram, por conseguinte, agentes motivadores da crise na relação porto-cidade, sendo a expressão mais clara desse processo o surgimento de rugosidades industriais e portuárias, as quais já representaram, no passado, funções fundamentais, mas que na contemporaneidade perderam expressividade, mesmo estando situadas em áreas privilegiadas de acessibilidade e infraestrutura urbana.

Desde os anos 1960, mas recorrentemente após os anos 1980 e 1990, que as rugosidades situadas em frentes d'água, tem sido, alvos de intervenções urbanísticas de propósitos reorganizacionais, visando sua reconstrução espacial, simbólica e sua readequação à lógica mercantilizada. A essas intervenções urbanísticas cotejamos o conceito dos grandes projetos urbanos (GPUs), que se trata de intervenções envolvendo usualmente a transformação de grandes áreas das cidades - as quais se encontram subutilizadas e obsoletas -, e a associação, no projeto, de um complexo grupo de atores a funções chave da gestão urbana (LUNGO; SMOLKA, 2005). Por mais que hajam dissidências e um amplo debate sobre a definição conceitual, entende-se aqui que uma das prerrogativas fundamentais dos GPUs é sua relação com o propósito do desenvolvimento econômico - sendo esse inclusive o 
principal discurso de seus defensores (OLIVEIRA, 2013) -, não somente sendo vinculado a uma organização ou ordenamento geográfico-espacial. Segundo Alvim, Costa e Alves (2018), GPUs que se materializam em frentes d'água são intervenções de grandes investimentos e parcerias entre setores públicos e privados, apresentando geralmente alta complexidade não somente financeira, mas também de constituição, implantação e de gestão.

Deste modo, entendendo, portanto, que a cidade "pós-industrial" se caracteriza não somente pelo aparecimento de rugosidades urbanas, mas também pela instituição de uma nova forma de pensar e produzir o espaço, num sentido empresarial e global. Projetos de transformação de waterfronts podem ser mirados como objeto de readequação do espaço rumo a uma maior conexão com os fluxos dentro da lógica capitalista. Intervenções desse porte se relacionam diretamente com a prerrogativa da cidade empresarial e tem adquirido cada vez maior recorrência, tanto em realidades centrais quanto em realidades terceiro mundistas. Isto posto, no item subsequente adentra-se mais sobre a temática dessa tipologia de projetos, chamando atenção para suas origens, seus conceitos e sua evolução histórica observada até o presente momento.

\section{Projetos urbanos em waterfronts: origens, conceitos e evolução histórica}

O termo frente d'água, ou "waterfront", como é conhecido internacionalmente, é bastante amplo e engloba qualquer território fronteiriço a um recurso hídrico, podendo este ser: um mar, um rio, um canal, um lago ou mesmo uma lagoa artificial. Tratase de um território intimamente ligado à paisagem e aos sistemas ambientais; apresentando, portanto, uma intima relação com bacias hidrográficas e com o ciclo hidrológico (COSTA, 2014, p.24).

A relação entre cidade e suas frentes d'água é reconhecida desde as antigas civilizações, sendo motivada por uma infinidade de questões, mas orientadas, sobretudo, pelo atendimento das demandas de um determinado período, como o abastecimento, a irrigação e o transporte. Ao longo do tempo, essas demandas foram sofrendo transmutações junto com as civilizações, e os territórios portuários de frentes d'água passaram a ser percebidos sob novas incumbências estratégicas, corroborando no último quarto do século XX, em uma dinâmica acentuada de deslocamento de suas funções para áreas periféricas e limites metropolitanos mais adequados às lógicas contemporâneas de produção. Conforme destacado por Talesnik e
Gutiérrez (2002), com a chegada do período pós-industrial, a situação hegemônica dessas áreas foi estremecida, configurando que "la industria se mudó de los centros de las grandes ciudades, y las otrora gloriosas zonas portuarias se convirtieron en áreas peligrosas y deterioradas (TALESNIK; GUTIÉRREZ, 2002, p.22).

Essa deterioração, o qual asseverou a obsolescência e o convertimento dessas extensões territoriais em áreas degradadas, favoreceu o enfraquecimento da relação porto-cidade e acabou, consequentemente, modificando o entendimento e atuação da gestão pública e dos atores sobre esse território. Segundo Cunha Junior (2018), a transformação no papel funcional das frentes d'água pode ser separada em duas fases substanciais: (1) entre as décadas de 1960 e 1970, quando ocorre a separação entre o porto e a cidade por fatores já discutidos na primeira sessão do trabalho; e (2) a partir dos anos 1980 e 1990, quando as administrações públicas e os mercados privados passam a difundir projetos de transformação nessas áreas, e a enxergar os waterfronts como espaços em potencial para a readequação urbana na dinâmica capitalista empresarial.

Neste sentido, os territórios das waterfronts podem ser entendidos como uma das principais oportunidades para a reinvenção das cidades contemporâneas (ALVIM; COSTA; ALVES, 2018). De acordo com os autores, esses territórios contam com a mais-valia da paisagem natural, e devido à presença da água, representam grande potencial de dinamização urbana, emergindo na contemporaneidade como ensejo favorável para a reconexão desses espaços com as cidades, e, consequentemente, com as águas que rodeiam e tanto favoreceram o surgimento dos núcleos urbanos. Os projetos que se propõe a transformar os waterfronts são, portanto, encarregados de promover modificações físico-naturais das bordas das águas que se localizam junto aos meios urbanos, mas também encarregados, em muitos casos, de substituir morfologias e usos subutilizados ou em processo de obsolescência.

De acordo com a sessão anterior, tais projetos, aqui estipulados sobre o conceito de GPUs e que se materializam sobre cidades industriais arrefecidas economicamente, realizam-se, majoritariamente, sob um panorama de investimentos e parcerias público-privadas, apresentando a partir disso uma grande complexidade no que diz respeito aos atores e aos interesses implicados. GPUs em frentes de água superam, portanto, a simples noção do desenho urbano, se apresentando também como ferramenta de análise, mas sobretudo de negociação entre os atores, 
interesses e condições locais e globais envolvidas aos projetos (ALVIM; COSTA; ALVES,2018). Sobre os mecanismos de administração pública e gestão urbana que vêm sendo empreendidos por essas transformações nas cidades, destacamos, essencialmente, a criação de equipes e setores específicos de gestão do território, os quais acabam mediando a dinâmica de apropriação, produção do espaço e funcionamento desses locais.

As origens das intervenções em waterfronts, embora envolvam uma base análoga à ascendência de uma cidade que caminha para a pós-industrialização e para a mercantilização urbana, ocorre de maneira distinta pelas metrópoles e cidades globais. Segundo Busquets (1997), o qual buscou sistematizar uma cronologia referente a tais intervenções, tais projetos podem ser afigurados a partir de três gerações dissidentes. Uma primeira, definida como "modelo americano" ou "modelo pioneiro", que ocorre por volta dos anos 1960 e 1970 e focaliza-se no turismo e no lazer a partir de estratégias comerciais e culturais que se utilizavam de grandes equipamentos urbanos como aquários, centros comerciais, centros de convenções, hotéis, dentre outros. De acordo com Cunha Junior (2018), trata-se de um modelo de reconversão monofuncional, que traz como resultado uma espécie de "ilha" isolada do resto da cidade. São exemplos dessa geração projetos como o Inner Harbor em Baltimore, o projeto para a orla marítima de Boston, além de diversos outros localizados em cidades como Nova lorque, Seattle, Portland e São Francisco.

Uma segunda geração, já a partir dos anos 1980, que emerge por diferentes países, mas sobretudo na Europa, através de profusas intervenções inspiradas pelo modelo norte-americano. É a partir dessa geração de projetos que se verifica uma proeminência no discurso sobre tais intervenções, ou seja, quando as mesmas passam a figurar internacionalmente como modelo de sucesso a ser aplicado nas cidades. A ênfase no turismo e no lazer do "modelo pioneiro" passou a ser acrescida pelos centros de negócios e por uma estratégia midiática orientada pela contratação de arquitetos internacionais para o desenvolvimento das obras. Além disso, houve nos casos europeus um uso mais amplo de territórios industriais subutilizados, os quais concentravam - em maior ou menor escala - valores históricos e patrimoniais, gerando inclusive súperas restrições e diretrizes para as intervenções. Exemplos vultosos desse período são os projetos das London Docklands em Londres, o $\underline{\text { Aker }}$ Brygge em Oslo, o Borneo-Sporenburg em Amsterdã.
E, por fim, uma terceira geração, onde destacam-se as propostas asiáticas, consideradas também as mais "arrojadas", pois além de materializar projetos sobre as frentes d' água, acabam por expandir o perímetro das intervenções para o interior das cidades e de seus recortes urbanos. Conforme levanta Cunha Junior (2018), nessa terceira geração, percebe-se uma ruptura com a cidade existente, e muitas vezes baseiam-se essencialmente na reconversão tecnológica e logística de uma cidade pretendida. Além disso, segundo Costa (2014), na Ásia, as intervenções geralmente apresentam escalas maiores, expandindo os projetos para uma área envoltória, e concentrando grande diversidade programática como atividades culturais, de lazer, de comercio, serviços, além de serem uma das pioneiras na pratica de integrar programas de habitação popular em seus contextos. Projetos emblemáticos dessa geração são os casos do porto de Kwai Chung em Hong Kong e o projeto do Cheonggyecheon Restoration, em Seul.

Para além das três gerações definidas por Busquets (1997), Cunha Junior (2018), aborda ainda uma possível "quarta geração", a qual faz referência aos países emergentes ou periféricos, a exemplo de Brasil, Argentina e Equador. Conforme aponta o autor, um ponto de ligação entre projetos dessa geração se refere as coalisões desenvolvidas entre o poder público e o capital privado, as quais representam em muitos casos uma ineficácia ou pouco alcance dos projetos nos âmbitos econômicos e sociais, entendendo que em países terceiro-mundistas, as tensões e as disputas que estão em jogo em intervenções desse porte se verificam de maneira mais desigual do que nos contextos centrais e asiáticos. Nesses contextos, temos os projetos emblemáticos do Porto Madeiro (Buenos Aires), do Projeto da Estação das Docas (Belém do Pará), e do Porto Maravilha (Rio de Janeiro), localizado sobre a frente d'água da baia de Guanabara e que figurará como elemento empírico de análise no decorrer deste artigo.

Pretende-se, nos itens subsequentes, focalizar análises sobre essa possível quarta geração de projetos em frentes d'água, discutindo especificamente a relação do Porto Maravilha com o decurso da gentrificação da zona portuária carioca, chamando atenção para as origens desse processo e reforçando que as alterações nas dinâmicas sociais da região vêm se materializando desde os anos 1990, fruto de diferentes gestões que contribuíram em maior ou menor escala, com o processo de mercantilização e de ascendência do empresariamento na produção do espaço urbano carioca. 


\section{Da ascensão empresarial ao projeto de transformação da zona portuária carioca: Os prefácios de César Maia}

A cidade do Rio de Janeiro entrou, particularmente na última década do século XX, em uma nova fase de investimentos e modificações no que se refere à produção de seu espaço. Os processos de empresariamento - norteados pelo ideário neoliberal de desenvolvimento - passaram a se materializar e abrir caminhos sobre recortes urbanos obsoletos ou de pouca relação com os fluxos de capital contemporâneos. Há, a partir deste momento, uma ruptura com o gerenciamento exercido anteriormente pelo Estado e uma ascensão progressiva às formas mercantilizadas de produção urbana, sendo destacados nesse processo, com forte protagonismo, o influxo dos mercados privados.

Evidencia-se que essa nova forma de produção do espaço - a qual aloca a cidade sob a perspectiva do funcionamento empresarial - tem início, sobretudo, no princípio dos anos 1990, sendo conectada em nível global com os processos de reestruturação econômica e divisão internacional do trabalho pós 1973, e em nível local com árduo e instável período inflacionário que o Brasil enfrentara na "década perdida"2. Frente a este cenário, a capital fluminense passou a empenhar estratégias intentando a superação de sua crise econômica - e consequentemente urbana -, sendo destacado nesse processo ênfases categóricas na técnica do planejamento estratégico, simbolizado, dentre outras características, pelas parcerias público-privadas (PPPs), as quais foram fortemente impulsionadas pelo "êxito" econômico da experiência de Barcelona, que desde 1992 figurara para a cidade como modelo próspero de desenvolvimento urbano.

Ainda que com raízes históricas anteriores, destaca-se que a proeminência dessa nova concepção de desenvolvimento urbano, se dá, efetivamente, a partir das gestões do ex-prefeito César Maia (PMDB; PFL; PTB; DEM), ocupante do cargo entre 1993-1996; 2001-2004; 2005-2008, os quais aglutinaram estratégias que figuram, neste trabalho, como essenciais para a discussão sobre uma possível origem dos processos empresariais na gestão urbana carioca. Mesmo que no final dos anos 1980, durante o mandato de Marcello Alencar (PDT, 1989 - 1993), sejam

${ }^{2}$ Termo habitualmente associado aos anos 1980, período em que países da América Latina como o Brasil, vivenciaram forte estagnação no que se refere ao desenvolvimento econômico. Trata-se de verificadas intervenções apercebidas como um presságio tímido da mercantilização do espaço - a exemplo do projeto "Rio-Orla" (1990-1992) que pretendeu urbanizar a orla da Barra ao Recreio dos Bandeirantes e reestruturar as praias do Leme a São Conrado - foi só a partir de 1993 que projetos guiados pela tendência empresarial tornaram-se expressivos e recorrentes, sendo inclusive apressurados, sobremaneira, pela busca de uma incorporação da capital fluminense na rota dos megaeventos internacionais.

Durante sua primeira gestão (1993-1996), as diretrizes de Maia foram norteadas, em grande parte, pela experiência do Plano Estratégico de Barcelona (1992), tendo como elemento impulsionador, a constante busca em recepcionar os Jogos Olímpicos de 2004. Com essa constante busca em vigor - que visava o Rio como sede olímpica - a cidade passou então a ser substanciada por projetos urbanísticos de readequação com o objetivo de prepará-la para este fim. São, portanto, originários dessa primeira gestão, sob tutela de Luiz Paulo Conde - que viria a ser eleito como prefeito na gestão subsequente - os projetos "Rio Cidade" (1995) - que objetivava requalificar eixos estratégicos de circulação viária e as infraestruturas de bairros de classe média e alta -, e o projeto "Favela Bairro" (1995) - que buscava a efetivação de serviços básicos de saúde, saneamento e infraestruturas em geral - os quais passariam a ser geridos sob o panorama público-privado - para populações de favelas. Tais projetos procriaram opiniões discordantes, sendo muito criticados pelos mais ortodoxos em virtude dos altos custos e ênfases nas obras, e sendo ovacionados pelos neoliberais, por "abrir" caminho sobre territórios muito simbólicos da paisagem carioca, afirmando, portanto, uma nova concepção urbana empresarial.

Já em sua segunda e terceira gestão (2001-2005; 2005-2008), sucedendo o apoiado mandato do seu ex-secretário de urbanismo Luiz Paulo Conde (PFL; 19972000), César Maia continuou sua abordagem à vista de uma possível inserção da cidade na rota dos megaeventos - concretizado pela escolha da cidade como sede dos jogos Pan-Americanos de 2007 - todavia, direcionou, como mais um elemento análogo à lógica empresarial de desenvolvimento, investimentos compenetrados no âmbito da segurança pública, visando reconverter aquilo que, para o mesmo,

um momento histórico de expressiva retração industrial, onde verificou-se crises econômicas variadas, forte inflação e baixo crescimento do Produto Interno Bruto (PIB). 
seria o grande obstáculo para a nova imagem da cidade: a violência. Foi, portanto, enfatizando investimentos sobre o ímpeto do medo, do inimigo e de um asseguramento aos megaeventos e aos fluxos capitalistas globais que os dois últimos mandatos do prefeito foram marcados, sendo associado a esse período a instituição da noção da "pacificação" como discurso e da militarização do espaço como prática. Exemplo claro dessa mixórdia é a criação das Unidades de Polícia Pacificadores (UPPs) em 2008, as quais se apresentaram como modalidade preventiva de segurança que buscava a inserção do policiamento comunitário, bem como o gerenciamento de serviços públicos em áreas marcadas por altos índices de criminalidade.

Evidencia-se, deste modo, que as gestões Maia fundamentaram a instituição de uma nova forma de desenvolvimento, pautada no protagonismo da iniciativa privada e na participação militar na produção e ocupação de determinados recortes urbanos. A partir deste novo contexto, que passou então a ser instituído "legalmente" desde 1993 e amplificado pela candidatura aos jogos olímpicos de 2004 e jogos pan-americanos de 2007, a cidade se postula também - já na primeira década do século XXI -, como sede da Copa do Mundo de 2014 e dos Jogos Olímpicos de 2016. As duas candidaturas acabaram deliberadas - já sob a luz das gestões de Eduardo Paes (PMDB; 2009 - 2016) -, congregando, para mais, diretas relações com os fluxos capitalistas internacionais e empresariais. Devido ao vultoso investimento que esses megaeventos concentravam, a transformação de determinados setores urbanos - que já vinha ocorrendo desde as gestões anteriores - tornou-se, maiormente, a pauta do desenvolvimento da cidade, e a ação militarizada amplificou-se sobre determinados recortes sob o discurso da garantia de efetivação dos megaeventos.

Surge assim em 2009, em vista desse panorama de adequação, a investida de transformação de um significativo cartão postal da cidade: o projeto para a readequação da zona portuária, denominado de Porto Maravilha. Situado na parte central do Rio, o perímetro da intervenção abrangeu cerca de 500 hectares, englobando os bairros da Saúde, Gamboa e Santo Cristo, além de setores do Centro, Caju, São Cristóvão e Cidade Nova. A caracterização da região como uma waterfront se refere à proeminência de atividades portuárias congregadas em períodos anteriores, mas essencialmente pela relação direta com as águas da baía de Guanabara (Figura 1), a qual abrange extensão de aproximados $400 \mathrm{~km}^{2}$ e que foi factualmente plano de fundo significativo da história da cidade e do Brasil. Conforme apontam Abrahão e Gandara (2014), a zona portuária concentra uma parte indispensável da memória brasileira, pois a partir das aberturas dos portos e da chegada da família real em 1808, passou a ocupar lugar central na ligação entre a colônia e o mundo exterior.

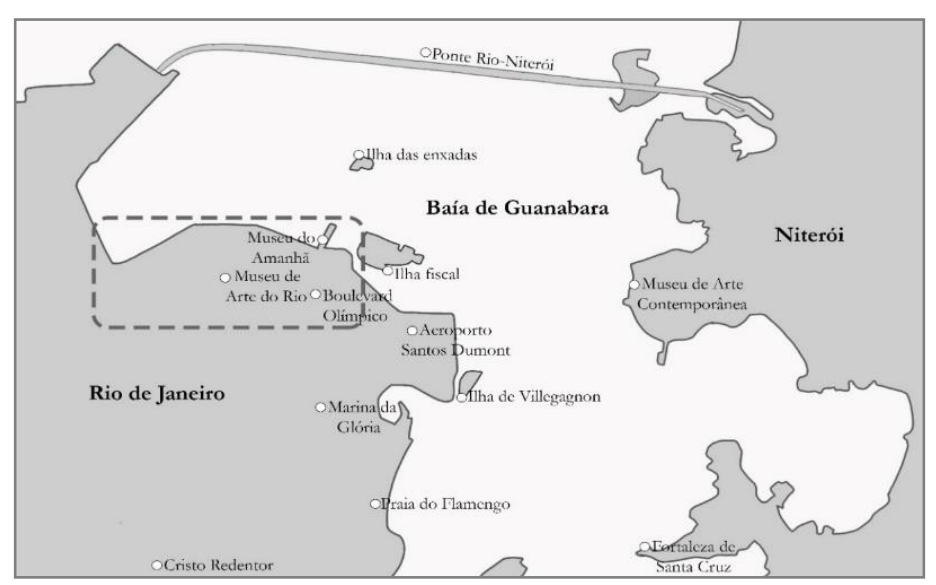

Figura 1: Localização da zona portuária no contexto da cidade. Fonte: Elaborada pelo autor a partir de base cartográfica do IBGE/2010 (2020).

Ao longo do século $X X$, o porto e consequentemente os bairros que compõem a zona, passaram a operar sua melhor e pior fase, respectivamente. Até os fins da década de 1970, a região esteve sempre atrelada a um símbolo de grande importância, pois, devido as exportações e o êxito produtivo fabril-fordista, o capitalismo enfrentara e refletira uma próspera fase na perspectiva do pós-guerra. Nada obstante, após os anos 1980, com a reestruturação econômica e com as novas perspectivas flexibilizadas, a capital fluminense deu início a construção de um novo porto fora do centro, o Porto de Itaguaí, mais moderno e automatizado e que possibilitara - seguindo o caminho de muitos países centrais - a transferência das atividades da zona portuária central para fora do município. Esse processo foi responsável por modificar de modo medular a relação entre cidade e o "antigo" porto, tornando a mesma mais distante, desconexa e mutuamente incompatível. 
Do ponto de vista da ocupação, torna-se importante considerar que, mesmo com as modificações que congregaram um aspecto de obsolescência para este território ao final do século XX, expressivos estratos sociais sempre se fizeram presentes na região, podendo ser destacados elementos de valor cultural como a Cidade do Samba e as escolas de tradicionais da região (Bloco afro Filhos de Gandhi; Escravos de Mauá), assim como elementos de valor histórico-social, ligados, sobretudo, a comunidades quilombolas e negras que ali se fixaram desde o princípio do século XIX. Caracterizados, principalmente, por grupos obreiros ligados ao porto e a atividade escravocrata, a ocupação da região mesmo que patente e significativa permaneceu, ao longo do tempo, marginalizada. Os bairros portuários acabaram desenvolvendo características próprias em função do seu isolamento relativo às últimas décadas do século XX, mediante a uma ausência de políticas inclusivas frente ao desinteresse do capital imobiliário pelos terrenos da região, antes considerados inseguros e abandonados (ABRAHÃO; GANDARA, 2014).

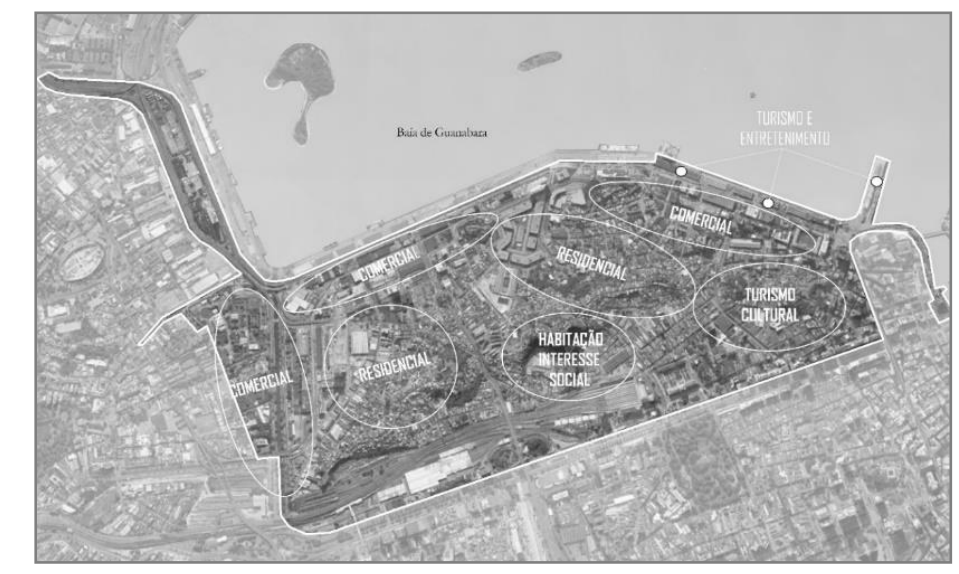

Figura 2: Perímetro da intervenção e seus usos pré-definidos. Fonte: Elaborada pelo autor (2020).

Mesmo havendo em períodos antecessores uma tentativa, ainda que minimizada, de transformar e reconectar essa região com o resto da cidade por projetos como "SAGAS" (1980) - que visou inventariar patrimônios arquitetônicos e culturais fixando normais de intervenção - e o projeto "Favela Bairro" (1995) - foi só a partir dos anos 2000, que a materialização de uma ampla transformação deste recorte adquiriu pujança no cenário político-econômico carioca. Sob o nome de Operação Urbana Consorciada Porto Maravilha, o projeto que previu a transformação da zona portuária foi, por conseguinte, criado através da lei municipal 101 de 2009 - sob gestão do então prefeito Eduardo Paes - e previa para esse território urbano novas atividades culturais, comerciais, habitação, habitação social, turismo e entretenimento.

Conforme apontam os próprios discursos dos atores público-privados envolvidos, a OUC Porto Maravilha, além de buscar modificar os aspectos simbólicos da rugosidade portuária, pretendia repovoar a região, triplicando o número de habitantes para 100 mil nos bairros adjacentes ao projeto. No próximo item, avança-se, portanto, em uma discussão acerca dos reflexos sociais gerados pela intervenção, chamando atenção para os processos de gentrificação que passam a ser empreendidos e ampliados em decorrência da transformação zona portuária.

\section{Projeto Porto Maravilha e seus reflexos de gentrificação}

[...] a gentrificação foi um processo que se propagou por toda a hierarquia das cidades: ele não ocorre somente nas maiores, mas também nos centros mais improváveis, tais como as antigas cidades industriais de Clavelan e Glasgow; em pequenas cidades como Malmo e Grenade; e mesmo nas pequenas cidades comerciais como Lancaster, na Pensilvânia, ou Eské Krumlov na Repúblicaa Checa (SMITH, 2006, p.62).

Antes de adentrar e discutir sobre os reflexos de gentrificação produzidos pelo projeto Porto Maravilha para os contextos sociais envoltórios à intervenção, depreendese aqui como fundamental definir do que se trata esse fenômeno e como esse texto se utiliza do mesmo para analisar o contexto carioca. Assim sendo, enfatiza-se que o fenômeno tem origem na literatura inglesa, sendo recorrentemente utilizado pela sociologia europeia para descrever processos de aburguesamento do centro das cidades de países centrais. Conforme apontam Pontes, García-Marín e MorenoMuñoz (2020), a gentrificação corrobora com a sobrevalorização de determinadas áreas urbanas, que antes concentravam aspectos de degradação, e que passam, na contemporaneidade, a assumir função turística, comumente patrocinada pelo poder público em parcerias com mercados privados. Segundo os autores, acontece uma "sustitución de determinados grupos sociales por otros, y también las 
actividades comerciales son reemplazadas por tiendas gourmet, fast foods y cadenas que comercializan productos similares en diversas ciudades del mundo." (PONTES; GARCÍA-MARÍN; MORENO-MUÑOZ, p. 152).

Entendendo, deste modo, o fenômeno como um processo de modificação e substituição das dinâmicas de composição locais em sentido a uma sobrevalorização da precificação da terra, objetiva-se neste item, destacar de que maneira a gentrificação se inicia e se torna proeminente na zona portuária carioca na medida em que a cidade empresarial se materializara por meio de políticas de governo voltadas para a revalorização e "adequação" de determinados recortes urbanos.

Isto posto, destaco aqui que as diretrizes e projetos iniciados ainda no final do século XX e desdobrados sobre as primeiras décadas do século XXI - "Rio-Orla (1990); "Favela-Bairro" (1995); "Rio-Cidade" (1995); "UPPs" (2008) - já vinham acarretando significativos e simbólicos processos de alteração e substituição das dinâmicas sociais de regiões da cidade. Nada obstante, com os desdobramentos da escolha da capital fluminense como sede dos megaeventos esportivos de 2007, 2014 e 2016 e com o advento do projeto Porto Maravilha como um dos signos da readequação da cidade "maravilhosa", tais processos adquiriram um padrão de recorrência mais impetuoso, significando, especificamente para um grupo de moradores da zona portuária, remoções habitacionais, pressões imobiliárias relacionadas a hiper-valorização do solo e um aumento significativo das técnicas e táticas de militarização do espaço. Versa-se, deste modo, nos parágrafos seguintes, discussões sobre tais processos que, em suma, já eram vivenciados anteriormente à intervenção, mas que com a consumação da mesma, passaram a compor de modo medular a ação dos atores urbanos sobre determinados setores da cidade em sentido a um "asseguramento" dos megaeventos e da "nova" imagem "maravilhosa" vislumbrada.

Visando, portanto, discutir e realçar os processos de remoção de populações que compõem a região portuária, se faz necessário, inicialmente, enfatizar um importante componente histórico localizado dentro do perímetro da intervenção: As favelas, e especificamente o morro da providência (Figura 3). Situado a cerca de $1500 \mathrm{~m}$ do porto, o morro, que se relaciona com a própria origem etimológica do termo "favela"- atribuído no início do século XIX pelos "vitoriosos" de Canudos - localiza-se na parte central da cidade, entre os bairros Santo Cristo e Gamboa, e congregava, pelo menos antes do projeto, aproximados 5 mil habitantes. Com os desdo- bramentos empresariais iniciados ainda na década de noventa e intensificados a partir de 2009, os moradores da providência passaram a enfrentar modificações constantes em suas dinâmicas. Tais modificações se relacionam, maiormente, aos desdobramentos do Porto Maravilha, mas sobretudo do "Morar-Carioca" (20092020), programa habitacional que pretendia vigorar como uma espécie de "retomada" do Favela-bairro (1995), porém mais excessivo e resoluto, visando até 2020, urbanizar todas as favelas do Rio de Janeiro.

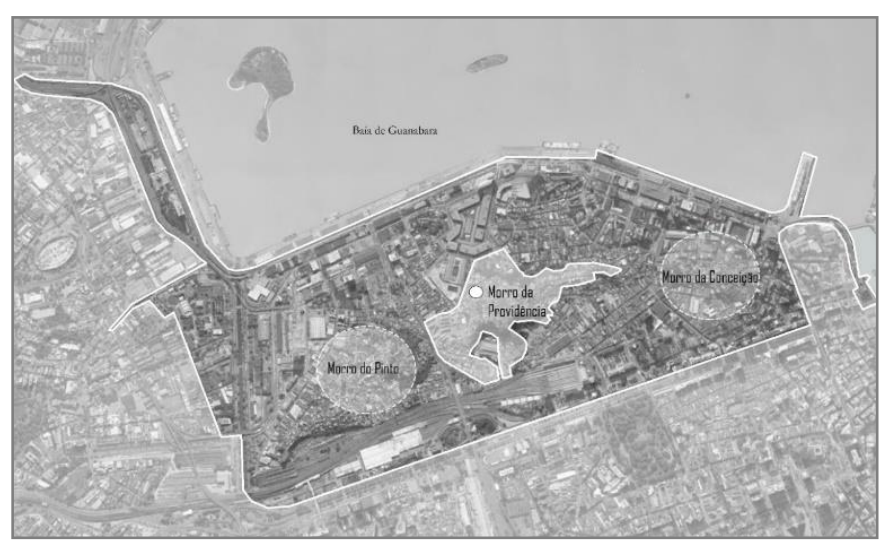

Figura 3: Localização do Morro da Providência na área do projeto. Fonte: Elaborada pelo autor (2020).

Conforme aponta Guterres (2016) o "Morar-Carioca" foi o único programa de moradia popular e de regularização de favelas que foi, recorrentemente, associado a remoção habitacional pelos moradores. Segundo a autora, no que se refere ao morro da providência, o programa previu a remoção de 605 famílias, as quais passaram a ser retiradas progressivamente segundo parâmetros de vulnerabilidade e risco. As remoções foram "balanceadas" com obras de infraestrutura - abertura de vias, implantação de teleférico e abertura de espaços para visitação turística - sempre sob 0 argumento de promover melhores condições de habitabilidade e mobilidade. $O$ destino dos moradores removidos passou a ser variado, e em muitos casos direcionados a regiões longínquas, sem muitas vezes, uma preocupação em alocar comunidades vizinhas nas mesmas proximidades. Segundo Rodrigues (2014), as regiões de Santa Cruz, Senador Camará e Bangu - todas essas localizadas a pelo 
menos $30 \mathrm{~km}$ de distância do morro da providência - foram os principais destinos oferecidos para os moradores, gerando indignação e consequentemente pouca adesão da população a essa proposta da prefeitura, sobretudo pela carência de infraestrutura e distância desses bairros da região central.

Além disso, como reflexo a essa proposição rígida e desacertada de realocação habitacional exercida pelo poder público, significativas parcelas da população local que tiveram seus destinos transferidos por terceiros seguem permanecendo na região, mesmo que em condições precárias. De acordo com estudo de Nascimento (2019), através de entrevistas não estruturadas com habitantes da rua do Livramento - localizada no perímetro da intervenção Porto Maravilha -, constatou-se que um significativo grupo de moradores em situação de rua que estão presentes na rua Pedro Ernesto (altura da Cidade do Samba) são ex-moradores do morro da Providência e seus subsetores, corroborando para a ausência de oportunidade e melhor direcionamento para os habitantes locais, os principais e verdadeiros desfavorecidos pela "adequação" mercantil da zona portuária.

Grosso modo, aponta-se que foi demarcada a remoção de aproximadamente metade da população da Providência, consumadas em grande parte de modo arbitrário, sem critérios de remoção homogêneos ou claramente pré-estabelecidos (GONÇALVES, 2013). Ademais, destaca-se o baixo percentual de unidades habitacionais propendidas pela intervenção que envolveu a zona portuária. Segundo Nascimento (2019), até o ano de 2017, apenas 68 unidades de HIS ${ }^{3}$ haviam sido licenciadas para região, das quais boa parte se encontrava atrasada. Ao comparar o número de unidades licenciadas pelo projeto com a quantidade de moradores removidos e realocados do morro, é notável uma clara incompatibilidade: há ausência de espaço para um número expressivo de indivíduos favelizados.

A pressão relativa ao deslocamento de determinados estratos sociais na região não acontece apenas nos casos de remoções diretas em função do risco e escalas de vulnerabilidade discutíveis. Há também quando os moradores não conseguem arcar com os ônus tributários resultantes das obras de reestruturação, que culminam, sobretudo, na valorização do território. A questão da pressão imobiliária e da hiper-

${ }^{3} \mathrm{HIS}$ ou habitação de interesse social é aquele tipo de habitação dirigida à população cujo nível de renda impede e afasta o acesso à moradia ofertada pelo mercado imobiliário. precificação da terra passa, por conseguinte, a compor a lógica empresarial da zona portuária. Com as obras do projeto e as diretrizes dos diversos programas empreendidos pelo poder público desde os anos 1990 - e intensificados a partir de 2009 , a região foi se modificando rumo a sua valorização, o que foi e continua a ser preocupante para os inquilinos dessa parte da cidade. Segundo Nascimento (2019), a partir de trabalho de campo realizado na região, verifica-se que o aluguel de algumas casas chegou a variar de 450 reais a 1.050 reais entre 2011 e 2016 - que pode até significar uma "melhora" econômica para os donos de imóveis - mas para os inquilinos, os quais estão submetidos ao aluguel, significa um cenário extremamente crítico. Segundo o autor, a cada ano os preços têm subido ainda mais, "em 2009, por exemplo, os sobrados eram vendidos por preços entre $R \$ 160000,00$ a 180 000,00. Em 2011, as vendas médias variaram entre $R \$ 350$ 000,00 e $R \$ 400$ 000,00. E, em 2012, houve vendas com o preço de 730 000,00 " (NASCIMENTO, 2019, p.51).

Como plano de fundo dessa espécie de "extinção" da providência e desse molde empresarial - correlacionado aos grandes eventos esportivos - destaca-se ainda o processo de ascendência da militarização do espaço - através de práticas e técnicas - as quais se tornaram sobressalentes a partir de $2008 \mathrm{com}$ as UPPs, ainda que desde os anos 1990 experiências de militarização já aconteciam inclusive na região da providencia, como a experiência dos GAPES e GPAEs que passaram a ser inseridos nas comunidades de morros e favelas desde 2002. Conforme apontado por Valente (2017, p.16), há pelo menos duas décadas que as "metáforas belicistas" tem sido empreendidas para tratar do "clima social" da capital fluminense - com inspiração em expressivos e claros cenários de guerra - a exemplo dos territórios palestinos ocupados por Israel e das ocupações norte americanas no Iraque e no Afeganistão. Segundo Barreira (2013), essa lógica militarizada, territorializante e excludente que culminou no projeto das UPPs, se projetou, sobretudo, sobre os locais que desempenham papel estratégico no molde empresarial urbano, o que explica factualmente a sua inserção na região portuária carioca.

Especificamente no que se refere ao recorte do morro da providencia, a UPP foi instalada em 2010 - através do policiamento permanente - objetivando a 
"pacificação" e a possibilidade de implantação de ações governamentais e privadas, sempre com a prerrogativa de melhora da condição de vida dos moradores. Sobre essa "pacificação" pretendida, Zaluar (2013) destaca que houve de fato uma expressiva queda, pelo menos até 2012, no que se refere ao número confrontos entre policiais e facções, nos homicídios e nos disparos de armas de fogo. Sem embargo, as tensões pré-existentes nunca desapareceram, e sim originaram novos conflitos - agora protagonizados por moradores e policiais -, resultados de "interesses divergentes ou de arbitrariedades e truculência ainda exercidas pela força policial que pretendia basear-se na proximidade com os moradores" (ZALUAR, 2013, p.4). Nas favelas com UPPs, houve uma espécie de reconfiguração das relações de poder, com o aparecimento novas lideranças e com o fortalecimento das antigas que estavam submetidas ao controle ou despotismo das facções criminais. Em outras palavras, com a "militarização da questão urbana" (SOUZA, 2008, p.104), as dinâmicas locais seguem modificando o meio e consequentemente metamorfoseando o território material e simbólico.

\section{Conclusões}

Diante do aqui exposto a respeito do empresariamento urbano, pode-se perceber que, muito mais que uma tentativa de atuar sobre espaços industriais subutilizados e obsoletos, os grandes projetos urbanos (GPUs) têm como propósito garantir condições necessárias para a exploração econômica das áreas centrais, visando a reconexão desses lugares - antes cognominados sob o signo do abandono e da obsolescência - com os fluxos internacionais contemporâneos. Nesse processo de transformação e adequação à lógica empresarialista e empreendedora, é ignorada, contudo, uma série de direitos daqueles cidadãos que historicamente habitam esses espaços precedentemente. Emerge, dessa conjuntura, uma afluência de violações referentes aos direitos e às dinâmicas locais, demonstrando que certas estratégias contemporâneas, intimamente ligadas ao empresariamento e aos fluxos globais, pouco favorecem as populações mais vulneráveis, sendo em muitos casos até responsáveis pelo alargamento de problemáticas predecessoras.

O projeto Porto Maravilha juntamente com diretrizes propendidas por gestões municipais anteriores - as quais prefaciaram a transmutação da lógica urbana carioca desde os anos 1990 - foi e tem sido responsável por substanciar modificações expressivas no que se refere às dinâmicas de populações envoltórias ao projeto.
Diante dessas alterações em sentido a substituições de fatores sociais e simbólicos, atribuiu-se aqui o conceito de gentrificação, se referindo ao processo de modificação socioespacial do território a partir da inserção de setores mais ricos em determinadas partes das cidades.

Ainda que, para diversos outros estratos sociais inseridos na zona portuária, o projeto represente melhorias sob consideráveis pontos de vista - infraestrutura urbana, enriquecimento cultural, paisagem e até mesmo valorização do solo -, a sua face perversa impôs e ainda continua a impor - categoricamente sobre os habitantes mais vulnerabilizados, sobretudo moradores de favelas - um padrão social e urbanístico exógeno e depreciativo com a cultura local e os contextos pré-existentes. Conforme aponta Smith (2006), essa imposição exógena - muito mais comum nos países centrais - também tem se tornado comum em países terceiro-mundistas, e embora os resultados de tais experiências sejam bastante diferentes e desiguais, todas acabam criando uma conexão muito complexa e disfuncional entre os contextos culturais e econômicos de nível local com as economias internacionais e globalizadas.

Sob esse ponto de vista conceitual, conclui-se que o projeto foi confeccionado tendo como público-alvo a classe média-alta, sem levar em consideração estratos sociais específicos - os mais pobres - e as problemáticas urbanas eminentes da localidade. A elevação do preço da terra foi, neste caso, aliada a uma atuação excessiva no que se refere à política habitacional exercida pelo poder público através do programa "Morar Carioca". A decorrência desse excesso pode ser compreendida pela remoção de quase metade da população do morro da Providencia, além de dezenas de moradores de rua, os quais tiveram suas inserções urbanas transferidas - ainda que arbitrariamente e violentamente - a outros territórios da cidade carentes de infraestrutura urbana.

Destaca-se ainda que, aliado à pressão das remoções habitacionais descendentes de uma tentativa de construção de uma nova imagem da zona portuária, a utilização do aparato militar como método de controle e desenvolvimento tem pautado desde os anos 1990 - mas sobretudo a partir de 2009 com as UPPs - a nova "normalidade" dos moradores de morros e favelas cariocas. Nesse novo "normal", gradualmente as dinâmicas tradicionais pré-existentes vêm sendo reprimidas e substituídas pelo âmbito do controle militarizado, mas sobretudo, pelo novo aspecto simbólico que a 
tutela continuada do policiamento corrobora aos moradores. A integração da favela como território da "cidade real" não vem, portanto, sendo efetivada, devido principalmente a uma ineficácia de participação social no desenvolvimento econômico que passou a ser propendido na zona portuária.

Mesmo não se caminhando aqui em direção a nenhuma conclusão pretensiosa sobre os fenômenos abordados, o que se pretendeu com este texto foi, além de discutir o contexto do empresariamento urbano através de projetos de revitalização de waterfronts, avançar sobre uma compreensão mais precisa a despeito dos reflexos resultante de tais intervenções sobre as populações mais vulnerabilizadas, ressaltando, especialmente a segregação e a inclusão social e territorial. Entendendo como clara a inevitabilidade da ação do Estado no que se refere ao provimento de investimento em políticas públicas direcionadas à melhoria de vida de populações que vivem em áreas precarizadas no país, percebe-se que a partir do momento em que esse mesmo Estado passa a se tornar agente promotor de mercado, sem que haja um direcionamento de políticas voltadas a populações desfavorecidas, podem, e provavelmente serão, agravados os reflexos lesivos desse processo, como é o caso da gentrificação.

Conclui-se, portanto, que, mesmo que existam diversos elementos importantes e qualitativos no que diz respeito ao projeto de intervenção para a zona portuária carioca, há uma inegável e imprescindível necessidade de adequar a inserção social e urbana de populações pobres em projetos desse porte em cidades que se propõem a transformar territórios subutilizados e obsoletos sob a lógica empresariamento e da mercantilização do espaço urbano.

\section{Referências}

ABRAHÃO, Cinthia M.; GANDARA, José M. Sobre desarrollo y turismo en procesos de intervención en waterfronts: Los casos de las ciudades brasileñas Recife y Rio de Janeiro. Estudios y perspectivas en turismo, Buenos Aires, v. 23, n. 2, p. 207232, 2014.

ALVIM, Angélica B.; COSTA, Rodrigo R.; ALVES, Karina D. Projetos urbanos em frentes d'água. Diretrizes e o potencial de transformação das orlas fluviais na cidade contemporânea. Arquitextos, São Paulo, ano 19, n. 222.01, nov. 2018. Disponível em: https://www.vitruvius.com.br/revistas/read/arquitextos/19.222/7170. Acesso em 10 de jul. 2020.

BUSQUETS, Joan. Los Waterfront de nuevo una prioridad urbanística. Mediterrâneo, Lisboa, v. 10, n. 11, 1997.

BARTOLY, Flávio. Debates e perspectivas do lugar na geografia. GEOgraphia, Rio de Janeiro, v. 13, n. 26, p. 66-91, 2011.

BARREIRA, Marcos. Cidade Olímpica: sobre o nexo entre reestruturação urbana e violência na cidade do Rio de Janeiro. In: Brito, F.; Oliveira, P.R. (Orgs). Até o último homem. São Paulo: Boitempo, p.129-168, 2013.

COSTA, Rodrigo R. Projetos urbanos em Frentes d'água: limites e desafios ambientais: 0 arco Tietê em São Paulo. Dissertação de Mestrado em Arquitetura e Urbanismo, Universidade Presbiteriana Mackenzie São Paulo, 2014.

CUNHA JUNIOR, Moisés F. Intervenções urbanas em Waterfronts: produção e apropriação do espaço público contemporâneo: o caso do projeto Porto Novo Recife - PE. Dissertação de Mestrado em Arquitetura e Urbanismo, Programa de pós-graduação UFPB, 2018.

DEL RIO, Vicente. Voltando as origens: a revitalização de áreas portuárias nos centros urbanos. Arquitextos, São Paulo, ano 15, n. 015.06, ago. 2001. Disponível em: https://www.vitruvius.com.br/revistas/read/arquitextos/02.015/859. Acesso em 15 de jul. 2020.

DIAS, Robson S.; NETO, Romeu. Uma análise das transformações espaciais decorrentes da passagem do regime fordista para os regimes flexíveis de acumulação. Vértices, Rio de Janeiro, v.6, n.2, p. 9-38, 2010. 
GONÇALVES, Rafael S. Porto Maravilha, renovação urbana e o uso da noção de risco: uma confluência perversa no morro da Providência. Libertas, Juiz de Fora, v. 13, n.2, p.175-207, 2013.

GUTTERES, Anelise dos Santos. O rumor e o terror na construção de territórios de vulnerabilidade na zona portuária do Rio de Janeiro. Mana, Rio de Janeiro, v. 22, n.1, p. 179-209, 2016.

HARVEY, David. Do gerenciamento ao empresariamento: a transformação da administração urbana no capitalismo tardio. Espaço e debates, São Paulo, v.16, n.39, p.48-64, 1996.

HALL, Peter. Cidades do amanhã: uma história intelectual do planejamento e dos projetos urbanos no século XX. São Paulo: Perspectiva, 2007.

LIPIETZ, Alain. Le tribut foncier urbain. Paris: François Maspero, 1974.

LUNGO, Mario; SMOLKA, Martin O. Land Value and large urban projects: The Latin American experience. Land Lines, Cambridge, v.17, n.1, p.3-6, 2005.

MARQUES, Paulo M. M. P. S. Transformações de frentes de água na cidade pós-industrial: o caso do HafenCity em Hamburgo. Dissertação de Mestrado integrado em Arquitetura apresentada à Faculdade de ciências e tecnologia da Universidade de Coimbra, 2018.

NASCIMENTO, Bruno P. Gentrificação na Zona Portuária do Rio de Janeiro: Deslocamentos Habitacionais e Hiper Precificação da Terra Urbana. Caderno Prudentino de Geografia, Presidente Prudente, v.1, n.41, p. 45-64, 2019.

OLIVEIRA, Alberto. Os grandes projetos urbanos como estratégia de crescimento econômico. EURE, Santiago, v. 39, n.117, p.147-163, 2013.

PONTES, Maria A.; GARCÍA-MARÍN, Ramon; MORENO-MUÑOZ, Daniel. Turismo, producción inmobiliaria y procesos espaciales: la difusión del modelo turístico español hacia Brasil. EURE, Santiago, v.46, n.137, p.135-156, 2020.

RODRIGUES, Nathália Mota. Remoções no Morro da Providência: o modelo hegemônico de modernização e a produção de um novo espaço. In: Encontro Regional de História da Anpuh-Rio: Saberes e Práticas Científicas, Rio de Janeiro, 2014.
SANTOS, Milton. A natureza do espaço: técnica e tempo, razão e emoção. São Paulo: Editora da Universidade de São Paulo, 2006.

SOUZA, Marcelo L. Fobópole: o medo generalizado e a militarização da questão urbana. Rio de Janeiro: Bertrand Brasil, 2008.

SCHNEIDER, Luiz C. Lugar e não-lugar: espaços da complexidade. Ágora, Santa Cruz do Sul, v.17, n.1, p.65-74, 2015.

SMITH, Neil. A gentrificação generalizada: de uma anomalia local à "regeneração" urbana como estratégia urbana global." De volta à cidade: dos processos de gentrificação às políticas de "revitalização" dos centros urbanos. São Paulo: Annablume , São Paulo. p. 59-87, 2006.

TALESNIK, Daniel; GUTIÉRREZ, Alejandro. Transformaciones de frentes de agua: la forma urbana como producto estándar. EURE, Santiago, v.28, n.84, p.21-31, 2002.

VALENTE, Julia L. O Rio de Janeiro no Urbanismo Militar e Empresarial. Revista Continentes, Rio de Janeiro, v. 10, p.7-26, 2017.

ZALUAR, Alba. Dilemas, desafios e problemas da UPP no Rio de Janeiro. In: XII Annual Internacional Conference of the Brazilian Studies Association (BRASA), Londres, 2014. 